\title{
«Digitalization» is a Modern Tendency in the Management of Economic Systems in the Russian Economy
}

\author{
Kotova O.V. ${ }^{1, *}$ Popova N.I. ${ }^{1}$ Vorotilova O.A. ${ }^{2}$ \\ ${ }^{1}$ Department of Finance, Money Circulation and Credit Ural State University of Economics \\ ${ }^{2}$ Department of Management and Finance of Production Systems Volgograd State Technical University \\ *Corresponding author. Email: kotova@usue.ru
}

\begin{abstract}
The article focuses on the consideration of the modern management trend of economic systems in the Russian economy - digitalization. «Digitalization» is defined as the reforming process of the socio-economic sphere by introducing digital technologies in all areas of human life and society. Digitalization has become the global development engine, providing the economic performance improvement and the enhance quality of life. Therefore, «digitalization» is considered as a trend of the country's economy effective development, a trend of the effective management of the country's economic systems. The article discusses the problems and benefits of the digital economy. An analysis of modern tendencies in the Russian digitalization development is also presented. An important aspect of the article is the consideration of digital technologies in the banking sector. Keywords: digitalization, management trend, banking sector and digital technologies, «smart bank»
\end{abstract}

\section{INTRODUCTION}

The key pillar of Russia's current economic development is digitalization.

The modern age is inconceivable without digital technology. Digital technologies attend in all areas of our lives and are the basis of their effective management. This process was named "digitalization" and has become a defining trend, a modern development stage of the economy for the coming decades.

The term «digitalization» of the economy and society is understood as the reform of the socio-economic sphere by introducing digital technologies for searching, processing, forming the exchange and transfer of information.

Currently it is difficult to imagine your life without the digital technologies using such as the Internet and the introducing new innovative products that have a significant impact on the economy development, the global financial system and, as a result, making any progress and improving the standards of living.

«Digitalization» is considered as a trend of the country's economy effective development, a trend of the effective management of the country's economic systems.
2. THEORETICAL AND METHODOLOGICAL ASPECTS OF "DIGITALIZATION" OF THE COUNTRY'S ECONOMY

The term «digitalization» first appeared in 1995, when the American computer scientist Nicholas Negroponte from the University of Massachusetts voiced the concept of «digital economy». The development strategy of the information society in Russia in the period 2017-2030, approved by Presidential decree on 05.09.2017 № 203, gives the following definition: «The digital economy is an economic activity in which the key factor in production is digital data, the processing large volumes and the using of analysis results which, compared with traditional forms of management, can significantly increase the efficiency of various types of production, technologies, equipment, storage, sale, delivery of goods and servants». Thus, the term «digitalization» means the process of transition to a digital economy [2].

The term «digitalization» is presently used in a narrow and broad sense. Digitalization in a narrow sense is the transformation of information into digital form, which should lead to cost reduction and the emergence of new means of carrying out any activity, to become an «assistant». The application of such information transformations in most cases leads to extremely positive consequences, which determine the using of the term in the broad meaning of the word.

The role of digitalization of the modern economy is extremely important now. It has become a development engine, improving the private aspects of the humankind 
economic and social life, increasing the quality and comfort of life. In the modern world, digitalization is broadly understood as the using of converting information into digital form. This entails a strengthening the effectiveness of the economy and an increase of the management quality of economic forms, which should ultimately improve the quality of life in the social and economic areas.

Responding to some requirements, digitalization will be the most important engine of world economic progress. Digital transformation should cover as many areas as possible, accompanied by its exceptionally effective application. The results of the analysis and information transformation should be accessible to everyone, the application should be clear to everyone.

Computing was used only in informatization and computerization, but with the technology development and the new tasks emergence, a need arose to solve economic issues, then digitalization replaced it. The ample resources of digitalization, which make it possible to present information in a convenient way, lead to the fact that there are already integral technological «habitat» environments (ecosystems, platforms) in which the user is able to collect for himself the necessary friendly environment (technological, instrumental, methodological, documentary, partnership, etc.) in order to solve already more significant and extensive tasks [2].

Among the many areas of the economy digitalization, the most important can be distinguished - this is product life cycle management, automation of manual labor using robots and electronic document management, cybersecurity, a flexible corporate culture based on the operational Internet interaction of geographically distributed employees and departments, and the using of information technologies in the banking sector and others. Analyzing the two digital economy definitions, it can be noted that each of them captures only some of its significant features. By collecting the most important features of the two determinations, holistic one can be created and gives the most accurate explanation of this term.

The digital economy is a system of socio-economic relations, which aims to the increasing effectiveness and competitiveness of the economy, showing an economic development modern model, in which increasing competitiveness and effectiveness becomes a vital necessity, due to the relevance of the evolutionary development stage of the socio-economic and industrial model of society.

The digital economy also covers the sphere of social life, production, business, science, management, households and individuals, reflecting the features of the new technological generation - the using of big data produced by various information systems, their subsequent processing and analysis, which will help to benefit from the information.

The digital economy focuses on the creation of new industries, business models, management models, new markets and new consumers, based on digital transformation, i.e. involving a transition from analog interaction and the usage of analog storage media to electronic interaction, which is based on the use of modern electronic means. It can be as innovative digital information and communication technologies, advanced electronic communication channels, electronic document management with electronic signature, electronic methods of accounting and processing, storage and information transmission.

The digital economy is based on the use of the latest mathematical methods and information processing models, and is implemented online through platforms such as the Internet, mobile and sensor networks.

The following definitions of the digital economy are currently official and taken at the governmental level in Russia:

- the digital economy is an economic activity in which the key factor in production is digital data, the processing large volumes and the using of analysis results which, compared with traditional forms of management, can significantly increase the efficiency of various types of production, technologies, equipment, storage, sale, delivery of goods and servants;

- the digital economy is an economic activity in which the production key factor is digital data. It contributes to the information space formation taking into account the needs of citizens and society to obtain high-quality and reliable information, the Russian Federation information infrastructure development, the creation and application of Russian information and telecommunication technologies, as well as the formation of a new technological basis for the social and economic sphere.

The concepts of «digitalization» and «digital economy» are different, but correlated. Digitalization is a wider concept. It is the digital economy basis, the development trend that determines the improvement of the economy and society. To summarize, digitalization is the primary modern trend in the economy and society development, organized on the transition to a digital format for the presentation and use of information aimed at increasing the economy capabilities, the effectiveness of managing all systems and improving the quality of life.

Digitalization contributes to the consistent improvement of all business processes in the economy and related social areas. Improving governance of economic systems is based on increasing the interchange speed, democracy and security of information and on increasing the importance of automation as a basis for digitalization [2].

Through the research, the theoretical and methodological base of the systematic approach, investment management, economic and mathematical modeling, economic analysis and the theory of market economy were used. The methodological base of the study relies on an analysis of the existing experience of using digital technologies in the activities of Russian organizations, as well as on an analysis of modern foreign and domestic practices of managing economic systems 
processes, increase the level of flexibility and «customization» taking into account the requirements of consumers;

- «customization» (from Customize- change something, configure) - this is the individualization process of products to specific needs, desires of specific consumers by making changes at the final stages of production;

- digital models development of new designed products and production processes;

- «digitalization» of the entire product life cycle (from a concept idea, design, production, operation, maintenance services to disposal). Cost rises with changes. The more it rises, the later it is introduced. Therefore, considerable attention is paid to the design phase, competitive feature or high consumer requirements are laid at this stage.

The accumulated practice of creation and operating smart factories in the manufacturing sector allows to identify three types of banks of the future by analogy: «digital», «smart», and «virtual».

«Digital Bank» aims to design a new generation banking product from the research and planning stage, when the basic principles of the service are laid down, to the stage of creation of a digital banking services layout, a digital body double and a prototype. «Digital Bank» reduces costs by $10-50 \%$, reduces production time by $20-70 \%$, leads to an increase in profits by $10-50 \%$.

«Smart Bank» focuses on the production of a new generation banking product from a single service to a finished product. The adoption of the «smart bank» leads to a 2-4-fold reduction in the production time of a banking product and a two-fold increase in profit.

«Virtual Bank» integrates digital and smart banks into a single network for the banking product production, from analyzing the needs of a banking product (service), creating a digital layout of banking services and further customizing them for the real needs of final consumer, to launching a finished banking service for a mass bank customer audience [11]. The virtual bank provides 2-4fold increase in productivity, reducing costs by $40 \%$.

Foreign experience in the creation and functioning of smart banks has shown their significant effectiveness both for the banking sector and for end users of the banking product, who get the maximum benefit from meeting their needs. This has an impact on improving the quality of banking services and improving the efficiency of banking services. 


\section{THE REZULTS DISCUSSION - «TRENDS IN THE DEVELOPMENT OF THE RUSSIAN ECONOMY DIGITALIZATION»}

Digital technologies are becoming an inseparable component of economic, political and cultural life, the economic entities of the Russian Federation and a driving force for the development of society in general. Russia is at the front of the modern civilization development, characterized by the rule of knowledge, science, technology and information in all areas of life. Studying foreign policy events and world trends, the Russian government is faced with the task of ensuring the country's competitiveness and national security, where the development of the digital economy plays an important role in solving these problems. Some elements of the digital economy have already been introduced and are functioning successfully. With the permission of electronic signatures, new forms of information interaction became available. Communication with government agencies has become much more comfortable and easier.

In considering the indicators of digitalization, such as its level and share in GDP, the technologies development and the speed of its adoption, it can be concluded that today Russia is not among the leaders in the digital economy development. The share of the digital economy in Russia's GDP is only $3.9 \%$, which is $2-3$ times lower than the leading countries. There are positive trends in the digital economy growth. In recent years, large digital companies have appeared in Russia, which subsequently became famous throughout the world. It is the world's largest independent online bank "Tinkoff Bank», which does not have physical branches, digital portals and ecosystems of «Yandex» and Mail.ru services, a manufacturer of navigational simulators and electronic navigation systems «Transas», Avito electronic classifieds site, and a social network «VKontakte», «Kaspersky Lab», a company for the production of digital security solutions, and many others.

The digital economy is currently the foundation of the country's economic development. Figure 1 shows the stages of the digital transformation of the Russian economy, from 1997 to the present.

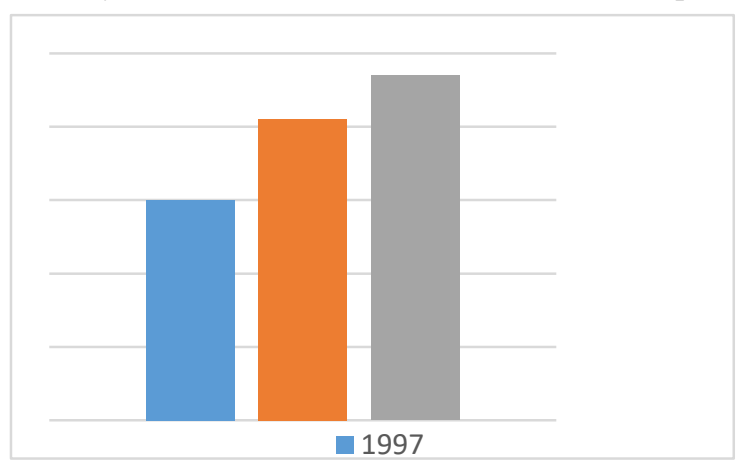

Figure 1 Stages of the economy digital transformation.
The first optimization stage of business processes and organizational structures took place, increasing the capacity utilization in 1997 . There were further automation and optimization of processes, as well as improved training and development of the financial system in 2007. Since 2016, Industry 4.0 has been developing in Russia, digitalization is taking place, a modern system of education, innovation, and science is developing as the digital economy «requires» «digital» skills.

The Russian digital economy has received significant development momentum in recent years. Private companies have achieved some success, the labor market is changing, and large-scale infrastructure projects are being implemented with state assistance. Such projects aim at increasing the availability of digitalization products for society and business. The Internet, mobile and broadband have been widespread. Today it is extremely difficult to assess the impact of the digital economy, its effectiveness. There is no single approach to measurement; methods for calculating key indicators may be inaccurate due to immaturity of models and insufficient analysis of all the features of the digital economy.

Despite the relatively high pace of the digitalization adoption, Russia lags behind the countries that are digital leaders in key indicators of the digital economy development, in particular from the European Union, as can be seen from Figure 2 .

Currently, the value of the key indicator for the digital economy development, as the ratio between the volume of the digital economy and the country's total GDP, is 3.9\%, which is about 2-3 times lower than in the EU countries. Building a digital economy in the Russian Federation will provide a number of potential advantages, for example, the use of digital technologies in both the public sector and business. The portal www.gosuslugi.ru has already been launched in the Russian Federation, which has helped to increase significantly the availability of various public services and the time to receive them has been reduced. Also in Russia, there are such «digital giants» as "Yandex», «Kaspersky», online order services, which also participate in the diversification of the Russian economy. Additionally, in Russia, a high rate of mobile communications entry, which includes an Internet service, was noted. Moreover, it is planned that by 2020, 95\% of the population of the Russian Federation will have access to the Internet.

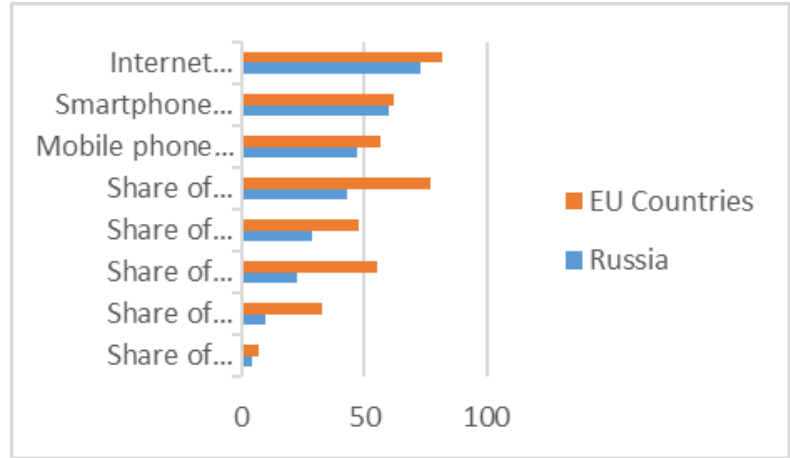

Figure 2 Access to digital services in Russia and the EU. 
The degree of digitalization has a big impact on the country's GDP. The influence of this indicator will be more and more significant each time. Since technology is being developed and implemented in all areas of life. Therefore, taking into account the existing problems, the government's policy of introducing and developing the digital economy is the primary and most important way to strengthen the strategic positions of the Russian Federation in the global economy.

The country government set a strategic goal for the development of Russia - tripling the volume of the digital economy from 3.2 trillion rubles in 2015 , up to 9.6 trillion rubles in 2025, in 2015 prices (Figure 4), which will require maintaining the average annual growth rate of the digital economy at $12 \%$, which was observed in 2010 2015. These results will be equivalent to an increase in the share of the digital economy from the current $3.9 \%$ to 8 $10 \%$ of GDP (depending on oil prices and other macroeconomic parameters), this corresponds to the current level of countries leading in the volume of the digital economy: USA, China and Western Of Europe.

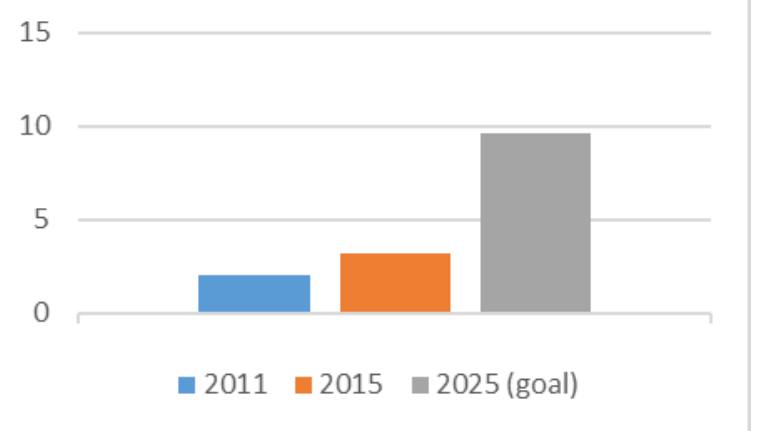

Figure 4 Strategic goal - tripling the volume of the digital economy in Russia.

Intensive digital technologies implementation will significantly reduce the backlog of Russia and ensure reliable development. According to the forecast for 2020, the share of the digital economy in Russia should increase. Such an economic forecast is associated with the possibility of automating existing processes, as well as using innovative and modern business models and technologies. For example, digital platforms, digital ecosystems, big data analysis, Industry 4.0 technologies such as 3D printing, robotics, the Internet of things [6].

\section{CONCLUSIONS}

«Digitalization» is understood the reform of the country's socio-economic system by introducing digital technologies for searching, processing, forming the exchange and transfer of information in order to increase and improve the people's quality of life. Digitalization is turning into a driver of global social development, which provides an increase in the efficiency of the economy and an improvement in the quality of life. Therefore, «digitalization» is considered as a trend of the country's economy effective development, a trend of the effective management of the country's economic systems.

For this, the digital information transformation must meet the following requirements: cover all spheres of human life; accompanied only by the effective use of its results; its results should be available to users of the converted information; not only specialists, but also ordinary citizens should use its results; users of digital information must have the skills to work with it.

An analysis of the development digitalization trends of the Russian economy has shown positive results that meet the requirements of the effective development of the country's economy, the effective management of economic systems. Among them are: the ubiquitous and accelerated process of transferring documents and communications to digital media, the introduction of electronic signatures, communication with the state is becoming possible on an electronic platform, the labor market is being reformed, and major government infrastructure and social projects are being implemented with government support to ensure a sufficient level of accessibility to digital services for society, the Internet, mobile and broadband are widely used. Digital technology has become the foundation of effective private business management. The volume of the digital economy in Russia has been growing rapidly in recent years. Digital technologies have most affected the banking sector. Smart banks are becoming the realities of the economic life of Russia.

Today it is extremely difficult to evaluate the effectiveness of the digital economy by coefficients and numbers. Due to the fact that there is no unified approach to assessment, a methodology for calculating key indicators has not been compiled that would clearly give an infographic of what is happening. An analysis of the digital economy is not enough now to draw any reasonable conclusions.

However, it can be already said for sure that digital technologies have firmly entered our lives, have become the basis of effective management, the modern trend of managing economic systems.

\section{REFERENCES}

[1] Kotova O.V., Vorotilova O.A. Solving the problems of municipal finance development is one of the most important areas of reforming the Russian Federation financial system and a prerequisite for a new the Russian economy industrialization.

[2] Khalin V.G., Chernova G.V. Digitalization and its impact on the Russian economy and society: advantages, challenges, threats and risks. [Text] / V. G. Khalin, G.V. Chernova // Management Consulting. 2018. - No. 16. - p. 46 - 63.

[3] Banki.ru. Available at: http://www.banki.ru (accessed 03/01/2019). 
[4] Bankinform. Ru. Available at: http://www.bankinform.ru (accessed 03/15/2019).

[5] Digitalization. Available at: http://www.uppro.ru/library/strategy/tendencii/cyfrovizaciyatrend.html. (accessed 10/11/2019).

[6] Five trends in the digital economy of Russia in 2018. Available at: https://rb.ru/opinion/ekonomikarossii/. (accessed 10/12/2019).

[7] Sygynbekova A. S. Digital economy: concept, prospects, development trends in Russia. [Text] / A. S. Sygynbekova // International scientific and technical journal "Theory, Practice, Innovations". - 2018 .-- p. 113.

[8] Gagarina, L.G. Information technology: textbook / L.G. Gagarina, Ya.O. Teplova, E.L. Rumyantseva et al ; Ed. L.G. Gagarina. - MOSCOW: ID FORUM: SIC INFRA-M, 2019 .-- 320 p.

[9] Gvozdeva, V.A. Informatics, automated information technologies and systems: textbook / V.A. Gvozdeva. Moscow: ID FORUM: SIC INFRA - M, 2019 .-- 544 p.

[10] Khadiullina, G.N. The market development features of information technologies in the modern Russian economy / G.N. Khadiullina, N.R. Shevko. // Socio-economic phenomena and processes. - 2017. No. 2 (060). - p. 143-146.

[11] Kuvayeva Yu. V. Digital economy: Concepts and Russia's readiness to transition. Izvestiya Uralskogo gosudarstvennogo ekonomicheskogo universiteta = Journal of the Ural State University of Economics, 2019, vol. 20, no. 1, pp. 25-40. DOI: 10.29141/20731019-2019-20-1-3. 